\title{
Flora do Rio de Janeiro: Alismataceae
}

\author{
Flora of Rio de Janeiro: Alismataceae
}

\author{
Yasmin de Mello Canalli ${ }^{1}$ \& Claudia Petean Bove $e^{1,2}$
}

\begin{abstract}
Resumo
O presente estudo tem como objetivo contribuir para o conhecimento das espécies da família Alismataceae no estado do Rio de Janeiro. O trabalho tem por base a análise morfológica de materiais depositados em herbários e coletas de campo, além de dados da literatura. Foram registradas nove espécies: Echinodorus grandiflorus, E. macrophyllus, Helanthium tenellum, Hydrocleys nymphoides, Limnocharis flava, Sagittaria guayanensis, S. lancifolia, S. montevidensis e S. rhombifolia, sendo que três são novas ocorrências para o estado. Descrições, ilustrações, dados sobre habitat e distribuição geográfica são apresentados.

Palavras-chave: chapéu-de-couro, plantas aquáticas, sudeste do Brasil, taxonomia.
\end{abstract}

\begin{abstract}
This study aims to contribute to the knowledge of the Alismataceae species in the state of Rio de Janeiro. The work is based on the morphological analysis of materials deposited in herbarium collections and field work, besides literature compilation. Nine species were recorded: Echinodorus grandiflorus, E. macrophyllus, Helanthium tenellum, Hydrocleys nymphoides, Limnocharis flava, Sagittaria guayanensis, S. lancifolia, $S$. montevidensis, and S. rhombifolia. Three of these species represent new occurrences to the state. Descriptions, illustrations, data on habitat, and geographic distribution are presented.
\end{abstract}

Key words: burhead, aquatic plants, Southeast Brazil, taxonomy.

\begin{abstract}
Alismataceae Vent.
Ervas aquáticas perenes ou anuais, emergentes ou flutuante fixas, monoicas, dioicas ou poligâmicas, com ou sem látex. Caule cormoide, rizomatoso ou estolonífero. Folhas espiraladas, em rosetas ou alternas, simples; emersas e flutuantes pecioladas, pecíolo cilíndrico a trígono, lâminas elípticas, lineares ou ovais, marcas translúcidas presentes ou não; submersas sésseis, lâminas elípticas, lineares ou lanceoladas. Inflorescência terminal, emersa, flutuante ou decumbente, simples ou ramificada, paniculada ou umbeliforme, com ou sem proliferações vegetativas, brácteas verdes lanceoladas, livres ou conadas. Flores actinomorfas hipóginas, uni ou bissexuais, sésseis a pediceladas; sépalas 3, verdes; pétalas 3, brancas, róseas ou amarelas com máculas vináceas, rosadas, amarelas ou alaranjadas; estames 3-numerosos,
\end{abstract}

livres, anteras 2-loculares, basifixas ou versáteis, deiscência rimosa, extrorsas, estaminódios presentes ou não, filetes lineares ou triangulares, glabros ou pubescentes; carpelos 3-numerosos, pistilódios presentes ou ausentes, livres ou unidos na base, ovário uni ou pluriovulado, estilete terminal ou ausente, estigma linear. Fruto aquênio ou folículo, agregado, com ou sem glândula.

Família com 15 gêneros (Matias et al. 2016) e cerca de 80 espécies (Pansarim \& Amaral 2005) de distribuição cosmopolita. No Brasil, cinco gêneros e 40 espécies (Matias et al. 2016). No Rio de Janeiro está representada por cinco gêneros e nove espécies. São encontradas em ambientes aquáticos de água doce ou salobra (Pansarin \& Amaral 2005). Frequentemente se reproduzem vegetativamente. Muitas espécies são cultivadas em aquários e lagos artificiais.

\footnotetext{
${ }^{1}$ Universidade Federal do Rio de Janeiro, Depto. Botânica, Museu Nacional, 20940-040, São Cristóvão, Rio de Janeiro, RJ, Brasil.

${ }^{2}$ Autor para correspondência: cpbove@hotmail.com
} 


\section{Chave para identificação dos gêneros ocorrentes no estado do Rio de Janeiro}

1. Flores unissexuais

5. Sagittaria

1'. Flores bissexuais.

2. Erva até $0,5 \mathrm{~m}$ alt.

3. Rizoma presente, pétalas amarelas ou amarelo-claras com mácula amarela.... 3. Hydrocleys

3'. Rizoma ausente, pétalas brancas .................................................................... 2. Helanthium

2'. Ervas $1-2 \mathrm{~m}$ alt.

4. Flores de pétalas brancas sem mácula, estaminódios ausentes ..................... 1. Echinodorus

4'. Flores de pétalas brancas a amarelas com mácula, estaminódios presentes .... 4. Limnocharis

\section{Echinodorus Rich. ex Engelm.}

Ervas monoicas, emergentes. Caule rizoma ou estolão. Folhas emersas, submersas ou flutuantes, pecioladas, lâminas lineares, lanceoladas, oblongas, ovais ou elípticas, lobos basais presentes ou ausentes, ápice obtuso a acuminado, base cordada a atenuada, marcas translúcidas pontos e/ou linhas, retículos ou ausentes. Inflorescência paniculada, ereta ou decumbente, ráquis e pedúnculo ereto, cilíndrico a trígono, liso a costado, brácteas 3-muitas, muitos ciclos de flores. Flores bissexuais, sésseis a pediceladas; sépalas côncavas, elípticas a ovais; pétalas brancas, róseas ou raramente amarelo-claras; estames 9-numerosos, estaminódios ausentes, filetes lineares, glabros, anteras lineares a orbiculares; carpelos numerosos, livres, uniloculares, uniovulados, estilete ausente, estigma inconspícuo. Fruto agregado de aquênios, costados, glandulares ou não.

Distribuído do norte dos Estados Unidos até a Patagônia, ca. 28 espécies (Lehtonen 2008). Ocorre em todos os estados do Brasil, porém não há registro para o Espírito Santo (BFG 2015), provavelmente por falta de coleta. No estado do Rio de Janeiro está representado por duas espécies. Além destas espécies, foi encontrado material herborizado de Echinodorus floribundus Seub. ex Warm. proveniente de cultivo no Horto Botânico do Museu Nacional e depositado no herbário desta instituição (R).

\section{Chave para identificação das espécies de Echinodorus do estado do Rio de Janeiro}

1. Marcas translúcidas presentes nas lâminas foliares

1'. Marcas translúcidas ausentes nas lâminas foliares
1.1. Echinodorus grandiflorus 1.2. Echinodorus macrophyllus
1.1. Echinodorus grandiflorus (Cham. \& Schltdl.) Micheli, Monogr. Phan. 3: 57. $1881 . \quad$ Fig.1a,e Nome popular: chapéu-de-couro.

Ervas 1,5-2 m alt., rizomatosas. Folhas emersas, bainha $8,5-22 \times 2,8-3,5 \mathrm{~cm}$, pecíolo cilíndrico, 11-72 × 0,6-3,5 cm, glabro ou com tricomas estrelados, lâminas ovais, $15-43 \times 7,5-34$ $\mathrm{cm}$, com ou sem tricomas estrelados, 11-14 nervuras, marcas translúcidas em pontos e linhas, base atenuada a cordada, ápice agudo ou arredondado. Inflorescência paniculada, 0,63-2 m, 3-27 ciclos, 4-25 flores cada, com ou sem proliferações vegetativas, ráquis cilíndrica a triangular 48-90 $\times$ 0,3-0,9 cm, pedúnculo cilíndrico, glabro, costado ou não; brácteas lanceoladas, 3-muitas, 1,5-2 × 0,5-0,7 $\mathrm{cm}, 13-20$ nervuras. Flores 1-2 $\times 2-4,2 \mathrm{~cm}$, pedicelo $2-80 \times 1 \mathrm{~mm}$; sépalas $0,5-0,9 \times 0,5-0,6 \mathrm{~cm}, 17-24$ nervuras; pétalas brancas $1,5-2,5 \times 1-1,5 \mathrm{~cm} ; 21-31$ estames, anteras $2 \mathrm{~mm}$ compr., filetes $3 \mathrm{~mm}$ compr.; carpelos numerosos, amarelos, $2 \times 1 \mathrm{~mm}$, com apículo superior-lateral. Aquênios 1-3 mm compr., com apículo, 3-4 costas, 2-3 glândulas lineares.

Material selecionado: Carmo, N. Armond 135 (R). Niterói, Pendotiba, Matapaca, estrada Caetano Monteiro, 22 $2^{\circ} 53^{\prime} 37.57^{\prime}$ 'S, 43002'12.70'W, 50 msm, 29.VIII.2015, T.S. Mendes 82 \& D.N.S. Machado (RFFP). Nova Friburgo, Córrego na rua D. João VI, 219, 11.XII.1999, R. Anjos et. al.10 (R). Paraty, Paraty-Mirim (-23.2531;44.6557), 2.XI.2014, Y.M. Canalli et al. 73 (R). Petrópolis, Correias, Fazenda Rogério Marinho, I.1972, J. Barcia 490 (R). Piraí, Estação Ecológica, mais ou menos $10 \mathrm{~m}$ do Clube de pesca, próximo à represa, junto a uma vala, 25.X.1985, M.M. Silva 203 \& R. Novais 3 (RBR). PORTO REAL, Rio Paraíba do Sul, 22.X.1981, J.P.P. Carauta et al. 3870 (GUA). Resende, às margens do Rio Bonito, 10 $\mathrm{km}$ da cidade de Resende, 5.VI.1984, J.P.P. Carauta et al. (GUA 27202). Rio Claro, Primeiro Distrido - Lídice, sítio da Barra, 25.XI.2001, F.B. Pereira 09/129 (RFA). Rio de Janeiro, Colônia Juliano Moreira, 30.IX.2004, S. Monteiro 
(RB 463801). Teresópolis, BR116, Km 735, estrada para o condomínio Retiro da Serra, 5.III.2014, Y.M. Canalli et al. 59 (R). Volta Redonda, Floresta da Cicuta, 12.X.1985, J.P.P. Carauta 5053 \& L.P.L. Fedulho (GUA).

Distribuída da América Central até o nordeste da Argentina e Uruguai (Haynes \& Holm-Nilsen 1994). No Brasil ocorre no Mato Grosso, Mato Grosso do Sul, nas regiões Sudeste (exceto Espírito Santo) e Sul (BFG 2015). No Rio de Janeiro ocorre nas quadrículas K22, O19, O23, P5, P6, P8, P17, S9, T18, U14, X3; de 0-800m alt. Coletada com flores nos meses de janeiro a novembro. Os tubérculos são comestíveis, utilizada em aquários, corantes, diurético, tônico, contra reumatismo, sífilis e antihipertensivo (Pott \& Pott 2000). Apesar da Lista do Brasil (BFG 2015). não reconhecer sua ocorrência no Rio de Janeiro, encontramos diversos registros nos herbários visitados, além de um novo registro para o município de Paraty em nossos trabalhos de campo.

1.2. Echinodorus macrophyllus (Kunth) Micheli, Monogr. Phan. 3: 50. 1881.

Fig. 1b,g,h

Ervas ca. $50 \mathrm{~cm}$ alt., rizomatosas. Folhas emersas, bainha 7-16 cm compr., pecíolo cilíndrico, 20-45 × 1,4 cm, costado, glabro a pubescente,
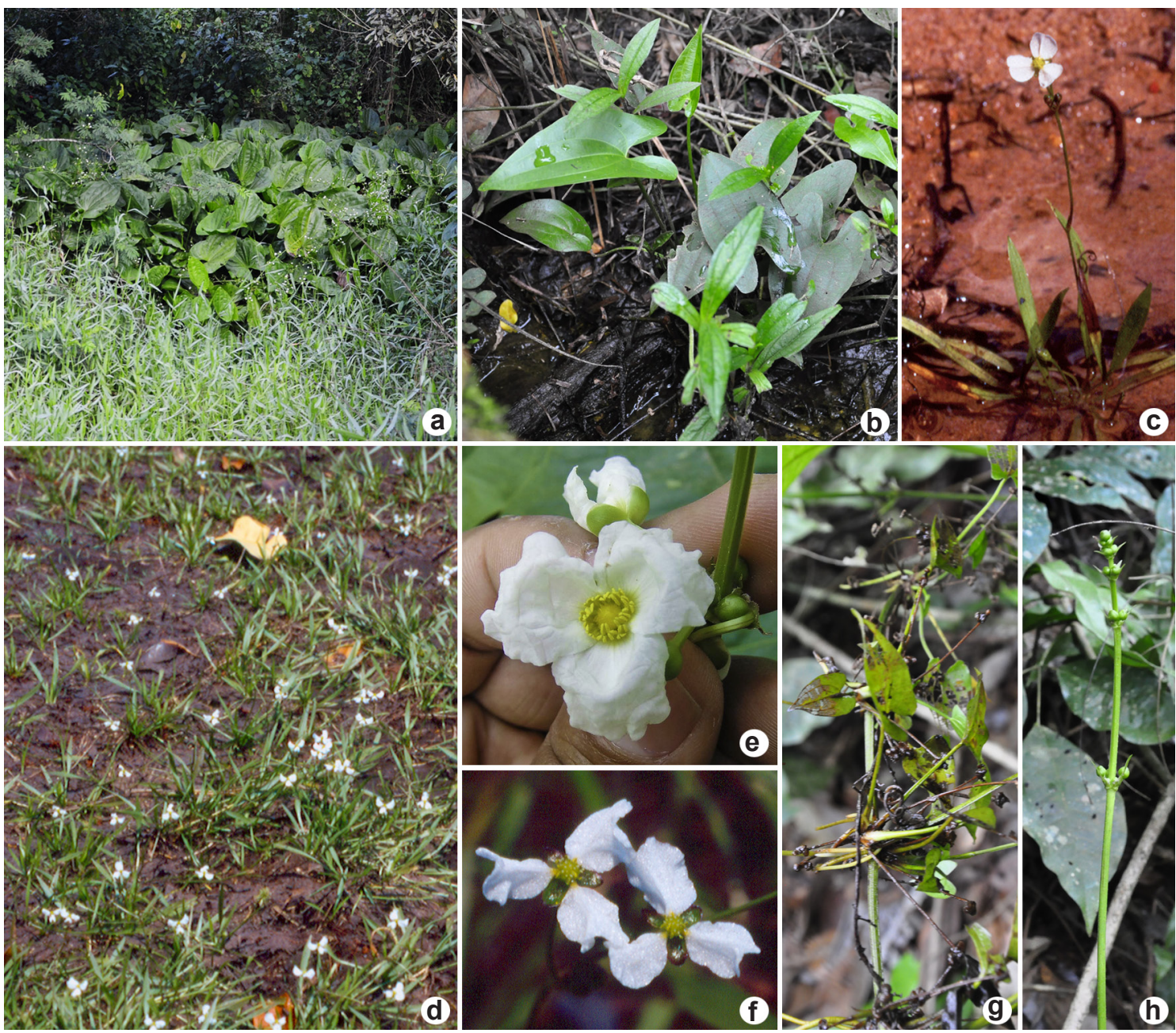

Figura 1 - Echinodorus grandiflorus - a. hábito (Canalli 74); e. flor (Mendes 82). Echinodorus macrophyllus - b. hábito; g. proliferações vegetativas na inflorescência; h. ápice de inflorescência em estágio inicial (Canalli 84). Helanthium tenellum - c. hábito; d. habitat; f. flor (Bove 550). Fotos: a-b,g-h. Y.M. Canalli; c-d,f. C.P. Bove; e. D.N.S. Machado.

Figure 1 - Echinodorus grandiflorus - a. habitus; c. flower (Mendes 82). Echinodorus macrophyllus - b. habitus; g. proliferous inflorescence; h. apex of inflorescence in early stage (Canalli 84). Helanthium tenellum - c. habitus; d. habitat; f. flower (Bove 550). Photos: a-b,g-h. Y.M. Canalli; c-d,f. C.P. Bove; e. D.N.S. Machado. 
lâminas ovais, $11-33 \times 7,5-28 \mathrm{~cm}$, glabras, base cordada a truncada, ápice obtuso, margem inteira, 9-13 nervuras, proeminentes na face abaxial, tricomas estrelados esparsos, marcas translúcidas ausentes. Inflorescência paniculada, 26-103,5 × 0,6 cm, 5-23 ciclos, 6-11 flores cada, com ou sem proliferações vegetativas, ráquis costada $23,5-37$ $\times 0,3-0,4 \mathrm{~cm}$, pedúnculo cilíndrico, costado, 23-35 $\times 0,1-0,3 \mathrm{~cm}$, brácteas 3-muitas, lanceoladas, $1 \times$ $0,3-0,5 \mathrm{~cm}, 13-14$ nervuras. Flores $0,5-1 \times 0,5-0,8$ $\mathrm{cm}$, pedicelo costado, $0,4-2,5 \mathrm{~cm}$ compr.; sépalas $0,3-0,5 \times 0,3-0,4 \mathrm{~cm}, 11-15$ nervuras; pétalas brancas 3-4 3 mm; 6-15 estames, anteras $1-2$ $\mathrm{mm}$ compr., filetes $2-3 \mathrm{~mm}$ compr.; carpelos numerosos amarelos $2 \times 1 \mathrm{~mm}$ com apículo superior lateral. Aquênio 2-3 mm compr., 2-4 costas, 0-15 glândulas.

Material selecionado: Cantagalo, 25.XI.2013, D. Hottz 262 et al. (RB). Piraí, Estação Ecológica de Piraí, 6.XII.1984, V. Pereira 70 (RBR). Resende, Itatiaia, Parque Nacional do Itatiaia, 18.IV.1954, H. Monteiro (RBR 28879). Rio das Ostras, Jardim Mariléa, segunda quadra próxima à estrada, 11.II.2000, A. Gil et al. 18 (R). Silva Jardim, REBIO Poço das Antas, atrás da casa do pesquisador, 19.IX.2015, Y.M. Canalli $85 \&$ A.V. $\operatorname{Greco}(\mathrm{R})$.

Material adicional: MATO GROSSO DO SUL: Corumbá, Pantanal do Miranda-Abobral. Passo da Lontra. Rodovia MS134, próximo à $10^{\mathrm{a}}$ ponte, no sentido Rio Miranda-Corumbá, em uma caixa de empréstimo

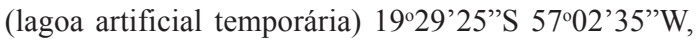
23.IX.1997, E.S. Guimarães 44 (R).

Distribuída desde a Guiana até o Brasil e Bolívia (Haynes \& Holm-Nilsen 1994). No Brasil ocorre em Roraima, Rondônia, Bahia, Minas Gerais, Rio de Janeiro, Paraná e Santa Catarina (BFG 2015). No Rio de Janeiro ocorre nas quadrículas K24, P5, P28, Q10, Q23; de 0-416 m de alt. Coletada com flores nos meses de fevereiro, abril, junho, agosto, setembro, novembro e dezembro. Folha utilizada para combater problemas nos rins e fígado, diurética e adstringente (Pott $\&$ Pott 2000). Também usada na fabricação de refrigerante e chás (Kinupp \& Lorenzi 2014).

\section{Helanthium (Benth. \& Hook. f.) Engelm. ex} J.G. Sm.

Ervas monoicas, emergentes ou submersas. Rizoma ausente. Caule pseudoestolão. Folhas emersas, submersas ou flutuantes, base atenuada, ápice agudo a acuminado, marcas translúcidas ausentes ou em linhas; folhas emersas pecioladas, lâminas lanceoladas a elíticas; folhas submersas sésseis, lâminas lineares. Inflorescência umbela, ereta ou decumbente, ráquis e pedúnculo ereto, brácteas 3-muitas, 2-3 ciclos de flores, com ou sem proliferações vegetativas. Flores bissexuais, pediceladas; pétalas brancas; estames 6-9, filetes lineares, glabros, anteras basifixas, glabras; carpelos numerosos, livres, uniloculares, uniovulados, estilete ausente, estigma inconspícuo. Fruto agregado de aquênios, costado, sem glândulas.

Distribuído no continente americano (Lehtonen 2008), com cerca de duas a nove espécies (Lehtonen \& Myllys 2008). No estado do Rio de Janeiro está representado por uma espécie.

2.1. Helanthium tenellum (Mart. ex Schult. f.) J.G. Sm., Man. Fl. N. States (ed. 2): 54. 1905.

Fig. $1 \mathrm{c}, \mathrm{d}, \mathrm{f}$

Ervas 5-12 cm alt.. Folhas emersas, pecíolo cilíndrico, 0-2,5 cm compr., lâminas emersas 0,6$19,5 \times 0,1-0,7 \mathrm{~cm}$, base atenuada, ápice agudo a acuminado, nervura1, marcas translúcidas ausentes. Inflorescência paniculada, 2-14 cm compr., 1-3 ciclos, 2-9 flores cada, com ou sem proliferações vegetativas, ráquis cilíndrica $3-12 \mathrm{~cm}$ compr., pedúnculo cilíndrico, glabro, 0,3-3,5 cm compr.; brácteas 3, lanceoladas, $0,3-4 \times 0,2 \mathrm{~mm}$. Flores $0,5-2 \times 0,7-4,2 \mathrm{~cm}$, pedicelo $0,1-4 \mathrm{~cm}$ compr.; sépalas $2-3 \times 1 \mathrm{~mm}$, pétalas $0,2-0,4 \times 0,2-0,3 \mathrm{~cm}$; 7-8 estames, anteras $1 \mathrm{~mm}$ compr., filetes $1 \mathrm{~mm}$ compr.; carpelos numerosos $1 \mathrm{~mm}$ compr. Aquênio obovado, 1mm compr., 3-4 costado, não-glandular. Material selecionado: Arraial do Cabo, Praia do Pontal, 1.I.1953, F.I. Segadas-Vianna 1313 (R). Campos dos Goytacazes, VII.1918, A. Sampaio 3086 (R).

Material adicional: BRASIL. BAHIA: Belmonte, Fazenda Belmonte, $3 \mathrm{~km}$ ao sul de Belmonte, 4.VIII.2006, E.P. Queiroz 1775 (R).GOIÁS: Estrada Jussara-Britânia (via Jacilândia), 12.XI.1999, C.P. Bove et al. 550 (R). MATO GROSSO DO SUL: Corumbá, Pantanal do Miranda-Abobral, Passo da Lontra, rodovia MS184, depois da curva do Leque, em uma Caixa de Empréstimo (lagoa temporariamente alagada), 10.IX.1997, E.S. Guimarães et al. 24 (R). MINAS GERAIS: Carmo do Rio Claro, fazenda Córrego Bonito, 8.IX.1961, A. G. Andrade 1174 \& M. Emmerich (R). Lagoa Santa, 8.VII.1932, A.C. Brade (R36051). SÃO PAULO: Serra da Bocaina prope limites com o estado do Rio de Janeiro, I.1925, A. Lutz 1767 (R).

Distribuída do nordeste dos Estados Unidos até o sul do Brasil. No Brasil nos estados do Pará, Goiás. Mato Grosso, Mato Grosso do Sul, minas Gerais, Rio de Janeiro, São Paulo, Paraná, Santa Catarina e Rio Grande do Sul (BFG 2015). No Rio de Janeiro ocorre nas quadrículas L34, T23; ao nível do mar. Coletada com flores em janeiro e julho. 


\section{Hydrocleys Rich.}

Ervas monoicas, flutuante fixas ou emersas, frequentemente com látex. Caule rizomatoso ou estolonífero. Folhas pecioladas, elípticas a reniformes, ápice agudo a arredondado, base cordada, arredondada, obtusa, truncada, sem pontuações translúcidas. Inflorescência umbela, terminal, ereta ou flutuante, com flores dispostas em ciclos, com ou sem proliferações vegetativas, brácteas elípticas a lanceoladas. Flores bissexuais, longo-pedunculadas; pétalas amarelas ou amarelo-claras com mácula amarela; estames e estaminódios numerosos, em ciclos, anteras 5-50, carpelos 3-numerosos. Fruto agregado de folículos, costados, sem glândulas.

Distribuído do México e Ilhas Caribenhas até a Argentina, ca. cinco espécies (Haynes \& Holm-Nilsen 1992). Ocorre em quase todo o Brasil, exceto em Roraima, Amapá, Acre, Rondônia, Maranhão, Tocantins, Espírito Santo e Rio Grande do Sul (BFG 2015). No estado do Rio de Janeiro está representado por uma espécie.

3.1. Hydrocleys nymphoides (Willd.) Buchenau, Index Crit. Butom. Alism. Juncag. 9. 1868.

Fig. 2a-d

Ervas ca. $40 \mathrm{~cm}$ compr., perenes, latescentes. Folhas flutuantes ou emersas, bainha 1,3-2 $\times$ $0,3-0,4 \mathrm{~cm}$, pecíolos cilíndrico $4,5-26 \times 0,3 \mathrm{~cm}$, lâminas orbiculares a reniformes, $2,1-17 \times 2,3-12$ $\mathrm{cm}$, base obtusa a truncada, ápice retuso a obtuso, 7 nervuras. Inflorescência emersa ou flutuante, 13-38 cm compr., 1-3 ciclos, 1-5 flores cada, pedúnculo cilíndrico $13-21 \mathrm{~cm}$ compr.; brácteas lanceoladas 3-5-meras, 1,2-5,5 × 1-1,5 cm, 11-14 nervuras. Flores 2,5-4 × 3-5,5 cm, pedicelo 3,5-18 $\times 0,2-0,6 \mathrm{~cm} ; 3-4$ sépalas $1-2,5 \times 0,5-1 \mathrm{~cm}, 14$ muitas nervuras; pétalas amareladas com mácula amarela na base 1,5-4,5 × 1,2-4,5 cm; estames e estaminódios numerosos, vináceos, filete linear, $3 \mathrm{~mm}$ compr., antera linear, $5 \mathrm{~mm}$ compr.; 4-8 carpelos vinho, livres, estilete terminal, estigma glanduloso. Folículos 2-2,7 × 0,3-0,7 cm, com apículo de $0,4-0,5 \mathrm{~cm}$ compr.

Material selecionado: Cabo Frio, Restinga de Cabo Frio, 20.I.1967, D. Sucre 1424 (RB). Cachoeiras de Macacu, Guapiaçu (REGUA), Fazenda São José, lago 1 (-22.4528; -42.7728), 27.VIII.2011, A.A.M. de Barros 4353 (RFFP). Campos dos Goytacazes, Próximo à Polícia Federal, 10.IV.2014, Y.M. Canalli et al. 62 (R). Magé, Raiz da Serra,1876, Schwacke 1406 (RB). Maricá, Parque Nanci, 16.IX.2012, R.R.Jr. Rodrigues 11 (RFFP). Rio Claro, Lídice, alagado na margem da rodovia Saturnino Braga, 1.XII.2014, A.R. Lourenço 55 (R). Rio de Janeiro, Jacarepaguá, rio das Pedras, avenida engenheiro Souza
Filho, próximo ao morro da Panela, 10.VI.1981, M.B. Casari 602 (GUA). Silva Jardim, Estrada para represa de Juturnaíba, Poço das Antas, 19.IV.2015, Y.M. Canalli $83 \&$ A.V. Greco (R).

Material adicional: BRASIL. ESPÍRITO SANTO: Santa Teresa, Estação Biológica Santa Lúcia, alagado proveniente de desvio do rio Timbuí, 18.VII.2002, C.P. Bove et al. 1063 (R). Mato Grosso: Estrada MozarlândiaNova Crixás km 18, 13.X.1997, C.P. Bove 276 \& S. Koehler (R).

Distribuída do Equador até o Suriname, Brasil e Argentina (Haynes \& Holm-Nilsen 1992). No Brasil ocorre no Amazonas, Bahia, Ceará, Paraíba, Pernambuco, Rio Grande do Norte, Goiás, Mato Grosso do Sul, Mato Grosso, Minas Gerais, Rio de Janeiro, São Paulo, Paraná e Santa Catarina (BFG 2015). No Rio de Janeiro ocorre nas quadrículas L34, Q20, Q21, R17, S08, T20, T27, U13; ao nível do mar. Coletada com flores de janeiro a setembro, novembro e dezembro. Novos registros para os municípios de Rio Claro e Silva Jardim são aqui relatados.

\section{Limnocharis Humb. \& Bonpl.}

Ervas monoicas, emergentes. Caule rizomatoso, raramente estolonífero. Folhas emersas longopecioladas, pecíolo triangular a sextavado, lâminas ovais a lanceoladas, ápice agudo a arredondado, base obtusa a cordada. Inflorescência umbela, ráquis ereta ou decumbente, cilíndrica, inflada, brácteas numerosas. Flores bissexuais, longo-pediceladas, pedicelo triangular, inflado; sépalas ovais a elípticas, ápice obtuso a agudo; pétalas brancas a amarelas, com mácula amarela na região proximal, ovais; estames numerosos, com estaminódios, filetes lineares, anteras lineares, carpelos numerosos, livres, estilete ausente. Fruto agregado de folículos, não costado, sem glândulas.

Distribuído do México, Ilhas Caribenhas até a Argentina e nos paleotrópicos, especialmente no sudeste da Ásia (Haynes \& Holm-Nilsen 1992). No estado do Rio de Janeiro está representado por uma espécie.

4.1. Limnocharis flava (L.) Buchenau, Abh. Naturwiss. Vereins Bremen 2: 2-4. 1869.

Fig. 2e-f

Nome popular: couve-d'água.

Ervas 30-70 cm alt. perene com látex. Folhas emersas, bainha $8,5-10 \times 1,9 \mathrm{~cm}$, pecíolo triangular $12,5-50 \times 0,8-2 \mathrm{~cm}$, lâminas ovais a elípticas, $7,2-29,5 \times 4,5-21 \mathrm{~cm}$, base obtusa a cordada, ápice arredondado a mucronado, 14-16 nervuras. Inflorescência 16-34,5 cm compr., 1-12-flora, 

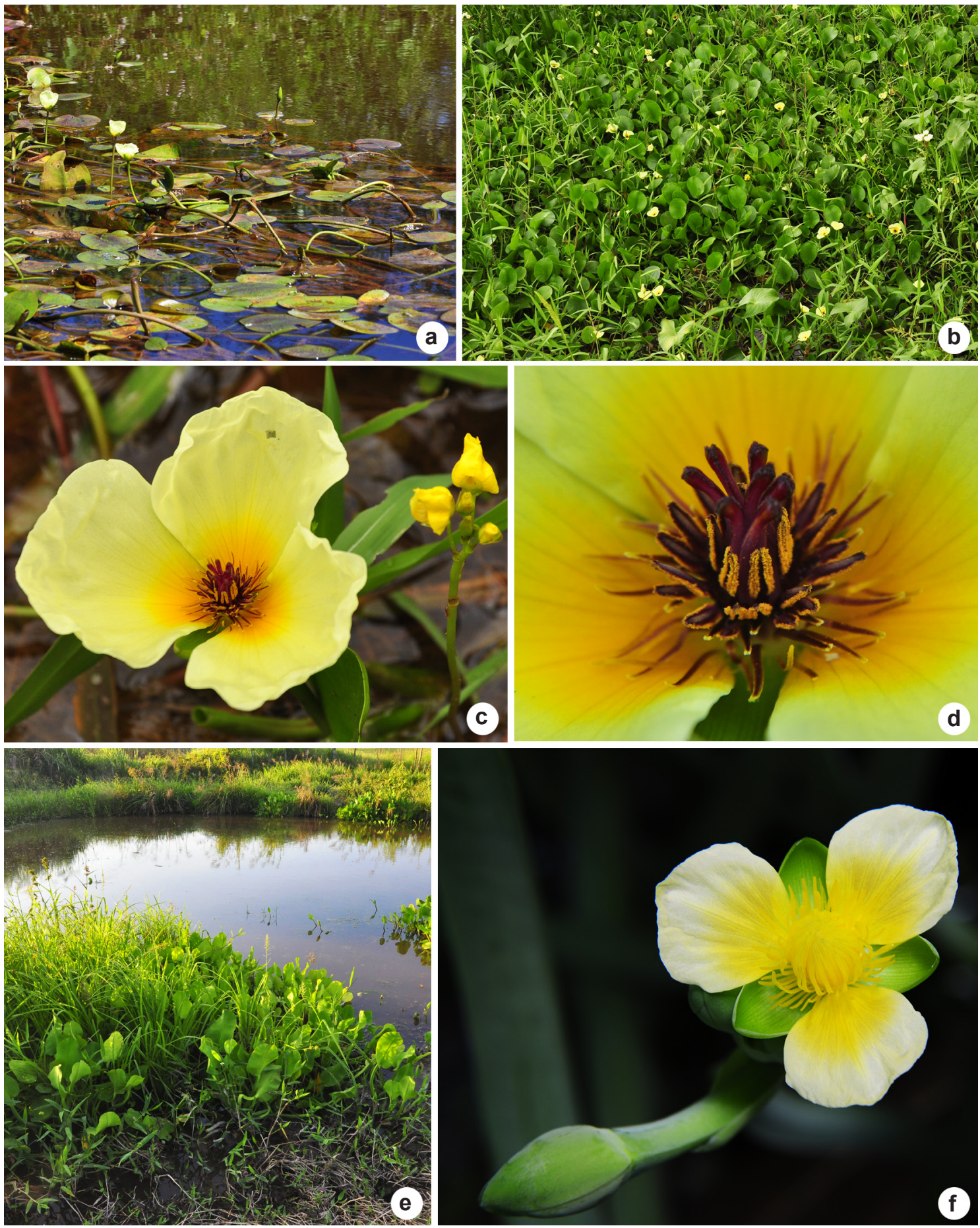

Figura 2 - a-d. Hydrocleys nymphoides - a. hábito com folhas flutuantes (Canalli 88); b. hábito com folhas emersas; c. flor em vista superior (Canalli 93); d. detalhe da flor, evidenciando carpelos livres, estames com anteras abertas expondo pólen e estaminódios (Canalli 93). e-f. Limnocharis flava - e. hábito; f. flor e botão floral (Canalli 82). Fotos: Y.M. Canalli.

Figure 2 - a-d. Hydrocleys nymphoides - a. habitus with floating leaves (Canalli 88); b. habitus with emerged leaves; c. flower in top view (Canalli 93); d. flower detail, showing free carpels, stamens with open anthers exposing pollen and staminodes (Canalli 93). e-f. Limnocharis flava - e. habitus; f. flower and floral bud (Canalli 82). Photos: Y.M. Canalli. 
ráquis triangular 16-31 ×0,5-1 cm; 4-11 brácteas lanceoladas, 12-27 × 4-10 mm nervuras numerosas. Flores 1,5 × 4,5 cm, pedicelo triangular inflado 2-6,8 $\times 0,4-1,5 \mathrm{~cm}$; 3 sépalas $12-26 \times 5-15 \mathrm{~mm}$; pétalas amareladas com mácula amarela na base 1,5-2,2 $\times$ 0,5-1,7 cm; estames e estaminódios numerosos, filetes 0,4-7 mm compr., anteras 1-2 mm compr.; carpelos de cor creme a amarelo-claros, 0,4-0,6 cm compr. Folículo semicircular, 1,5-2 × 0,7-1 cm. Material selecionado: Armação de Búzios, Reserva Tauá, 4.IV.2004, T.T. Carrijo et al. 50 (RB).Campos dos Goytacazes, Lagoa Feia, rio de Tocos, 10.III.1981, D. Araújo 4326 (GUA). Carmo, Serra da Babilônia, perto do córrego da Glória, 28.III.1984, J.P.P. Carauta 4664 (GUA). Itaboraí, João Caetano, próximo à BR-493, -22.7258, -42.9516, 11.VII.2014, A.R. Lourenço 23 (R). Magé, Córrego em Raiz da Serra, próximo à Duque de Caxias, no leito de um córrego temporário com pouca água, 11.VIII.2001, S. Bastos 4 (R). Nova Iguaçu, Vila de Cava, rua Coronel Alberto de Melo, 801, entre o sítio Sol da Justiça e o viaduto da rodovia Raphael de Almeida Magalhães (Arco Metropolitano), -22.6856, -43.4468, 13.II.2015, Y.M. Canalli 79 \& A.V. Greco (R). Rio de Janeiro, Distrito Federal (Rio de Janeiro), Jacarepaguá, lagôa, 1911, M. Mattos (R52930). São Gonçalo, Ipiíba, Rio Aldeia, 15.V.2007, M.G. Santos 2083 (RFFP). Silva Jardim, BR101, Km 206, próx. REBIO Poço das Antas, -22.5091, -42.2901, 18.IV.2015, Y.M. Canalli 80 \& A.V. Greco (R). Tanguá, Cachoeira de Tomascar, 22\%49'40.75"'S 42³9'23.22'”, 188 msm, 29.VIII.2015, D.N. S. Machado 752 et al. (RFFP).

Distribuição ampla, do México à Argentina e sudeste da Ásia (Haynes \& Holm-Nilsen 1992; Pott $\&$ Pott 2000). No Brasil ocorre em quase todos os estado, exceto em Roraima, Alagoas, Sergipe, Santa Catarina e Rio Grande do Sul (Matias et al. 2016). No Rio de Janeiro ocorre nas quadrículas K22, K34, Q18, Q21, S13, S18, S21, S28, V13, 0-188 m alt. Estes registros consistem em novas ocorrências para os municípios de Itaboraí, Nova Iguaçu e Silva Jardim. Coletada com flores de janeiro a abril, junho, agosto e outubro. Flores e botões utilizados na alimentação (Kinupp \& Lorenzi 2014).

\section{Sagittaria L.}

Ervas monoicas, dioicas ou poligâmicas, emergentes. Caule rizomatoso ou tuberoso. Folhas emersas ou submersas, pecioladas ou sésseis, ovadas, lanceoladas, reniformes, ápice agudo ou arredondado, base cordada, arredondada ou sagitada, sem marcas translúcidas. Inflorescência racemosa, ráquis e pedúnculo emerso ou flutuante, brácteas lanceoladas, livres ou conadas na base, muitos ciclos de flores. Flores unissexuais, inferiores pistiladas com ou sem estaminódios e superiores estaminadas com ou sem pistilódios, pediceladas, sépalas ovadas a lanceoladas, pétalas brancas com ou sem mácula vinácea, estames 6-numerosos, filetes lineares a dilatados, anteras basifixas, carpelos numerosos, uniloculares, uniovulados, estilete ausente. Fruto agregado de aquênios, não costados, com ou sem glândulas.

Distribuído no continente americano, ca. 24 espécies (Matias \& Irgang 2005). No Brasil está representada por seis espécies. No estado do Rio de Janeiro está representado por quatro espécies.

\section{Chave para identificação das espécies de Sagittaria do estado do Rio de Janeiro}

1. Ervas com ca. 1-1,5 $\mathrm{m}$ alt., pétalas sem máculas 5.2. Sagittaria lancifolia

1'. Ervas com menos de $80 \mathrm{~cm}$ alt., pétalas com máculas.

2. Folhas flutuantes

5.1. Sagittariaguayanensis

2'. Folhas emergentes.

3. Folhas ovadas, base sagitada

5.3. Sagittaria montevidensis

3'. Folhas elípticas, base cuneada, truncada ou cordada 5.4. Sagittaria rhombifolia

5.1. Sagittaria guayanensis Kunth, Nov. Gen. Sp. [H.B.K.] 1: 250 (ed. q ${ }^{\circ}$ ); 199 (ed. fo). 1816.

Fig. 3a-b

Ervas $12-61 \mathrm{~cm}$, flutuantes, monoicas, latescente ou não. Folhas flutuantes, bainha $50-80 \times$ 5-7 mm, pecíolo cilíndrico costado 5-21 $\times 0,2-0,3$ cm, lâminas ovadas $18-50 \times 8-40 \mathrm{~mm}$, base cordada, ápice agudo a arredondado, 6-11 nervuras; folhas submersas, sésseis, lineares 40-60 × 5-6 mm, ápice base atenuada, acuminado a agudo, 3 nervuras.
Inflorescência 4,5-25 × 0,3-0,4 cm, 2-5 flores; brácteas 3-4 lanceoladas, $0,5-2 \times 0,4-1 \mathrm{~cm}$, nervuras numerosas. Flores $1-1,5 \times 0,4-0,5 \mathrm{~cm}$, pedicelos $1,2-$ $1,5 \times 0,2 \mathrm{~cm}$ com tricomas; sépalas $0,8-1 \times 0,5-0,6$ $\mathrm{cm}, 16$ vmuitas nervuras; pétalas brancas com máculas amarelas ou vinho na base $1 \times 0,5 \mathrm{~cm}$; pistiladas, carpelos $1 \mathrm{~mm}$, ápice apiculado, anel de estaminódios presente; estaminadas, 5-7 estames, amarelos, $1 \mathrm{~mm}$ compr., pistilódios presentes. Aquênio de margem equinada, ápice apiculado, $2 \times 2 \mathrm{~mm}$. 

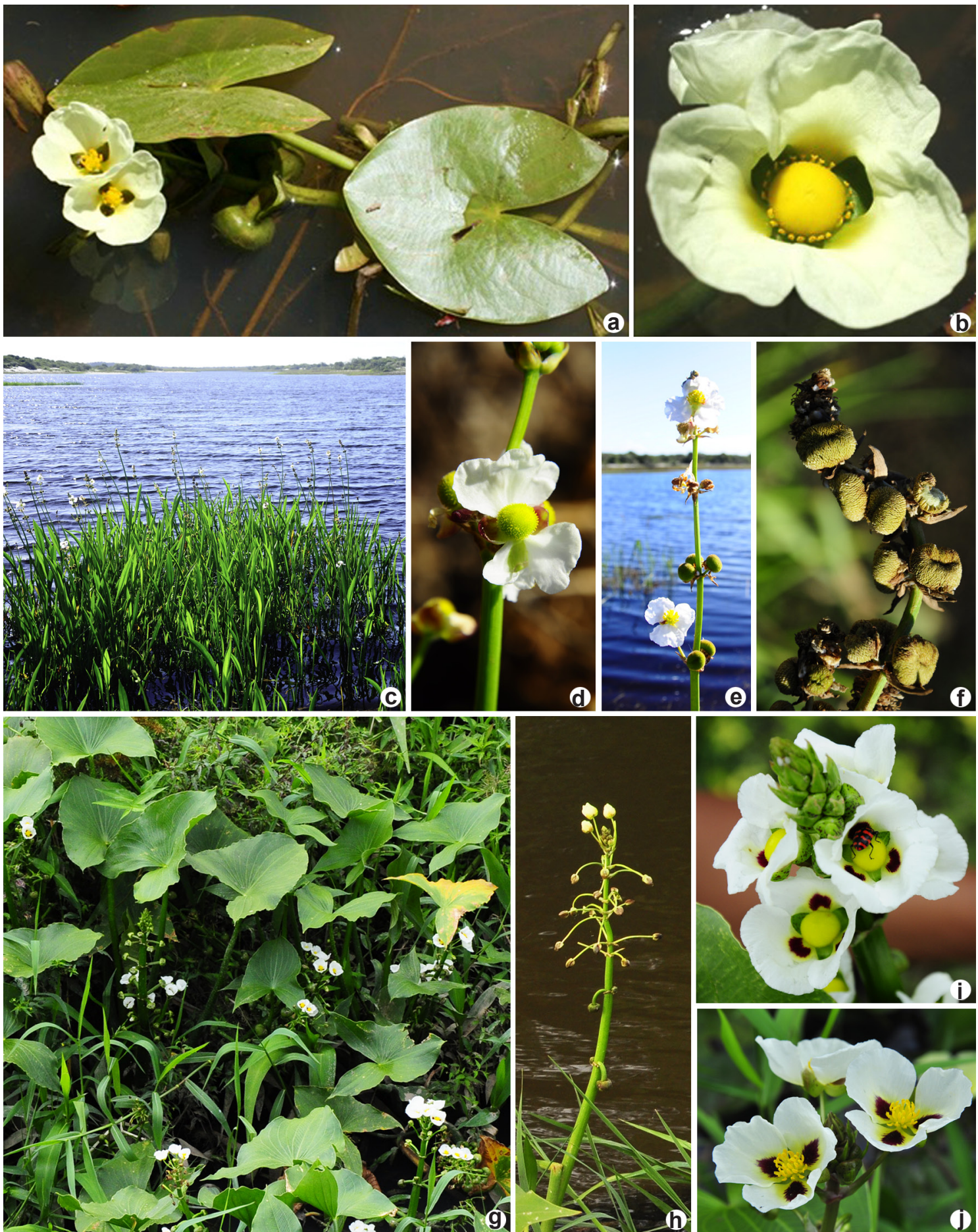

Figura 3 - a-b. Sagittaria guayanensis - a. folhas, flor masculina e fruto; b. flor feminina (Bove 200). c-f. Sagittaria lancifolia - c. hábito dentro de lagoa (Canalli 71); d. flor feminina (Canalli 78); e. flor masculina (Canalli 71); f. infrutescência (Canalli 78). g-j. Sagittaria montevidensis - g. hábito (Canalli 76); h. inflorescência em fase masculina na porção superior e frutos na parte inferior; i. flor feminina; j. flor masculina (Canalli 93). Fotos: a-b. C.P. Bove; c-j. Y.M. Canalli.

Figure 3 - a-b. Sagittaria guayanensis - a. leaves, male flower and fruit; b. female flower (Bove 200). c-f. Sagittaria lancifolia - c. habitus in lagoon (Canalli 71); d. female flower (Canalli 78); e. male flower (Canalli 71); f. infrutescence (Canalli 78). g-j. Sagittaria montevidensis - g. habitus (Canalli 76); h. inflorescence in male phase in the upper portion and fruits at the bottom; i. female flower; j. male flower (Canalli 93). Photos: a-b. C.P. Bove; c-j. Y.M. Canalli. 
Material selecionado: Cambuci, Funil, RJ 194, margem do rio Pomba, 24.VIII.1981, M.B. Casari 585 (GUA). Nilópolis, Parque Natural do Gericinó, 24.VII.2014, I.C. Silva 92 (R).

Material adicional: BRASIL. BAHIA: Estrada entre Urandi e Guanambi, a $8 \mathrm{~km}$ de Pindaí, 23.I.2002, C.P. Bove et al. 969 (R). Estrada Itaetê-Iaçú a 80,6 km de Itaetê, poça com ca. de $50 \mathrm{~cm}$ de profundidade, 13.I.2001, C.P. Bove et al. 816 (R). Goiás: Estrada Aragarças-Aruanã, Km 11, 13.X.1997, C.P. Bove et al. 281 (R). Estrada Jussara-Britânia, Km 54,4, lado direito da estrada, 28.V.1997, C.P. Bove 200 \& S. Koehler (R). Estrada Jussara-Aragarças, Km 100, lado esquerdo da estrada indo, 26.V.1997, C.P. Bove 189 \& S. Koehler (R). Estrada Araguapaz-Aruanã, Km 11, 13.X.1997, C.P. Bove et al. 281 (R). Mato Grosso: Estrada de Paranatinga para Canarana, Km 151, 12.II.1993, C.P. Bove et al. $95(\mathrm{R})$. Minas Gerais: Morrinhos, lagoa da Piranha, 4.V.1912, A. Lutz 38 (R). São Paulo: São José dos Campos, banhado, 26.IV.1998, C.P. Bove 308 (R).

Distribuída no sul dos Estados Unidos e do sul do México ao Paraguai e Argentina (Pott \& Pott 2000). Segundo Matias et al. (2016) ocorre em quase todos os estados do Brasil, exceto no Amapá, Rondônia, Paraíba, Espírito Santo, Rio de Janeiro, São Paulo e região Sul. No entanto, encontramos registros para o estado do Rio de Janeiro, nas quadrículas H28, S18, ao nível do mar. Encontrada com flores no mês de julho e agosto. Pode ser utilizada como suplemento alimentar, os tubérculos servem como alimento para humanos e animais, as pétalas como analgésico e o extrato para dor de ouvido (Burkill 1985). Estes registros consistem em um nova ocorrência para o estado.

5.2. Sagittaria lancifolia L., Syst. Nat. (ed. 10) 2: 1270. 1759.

Fig. $3 \mathrm{c}-\mathrm{f}$

Ervas ca.1,5 cm, emergentes, monoicas, latescente ou não. Folhas emersas, bainha $15-42 \times$ 1,8-4 cm, pecíolo cilíndrico, $15-112 \times 1,7-4 \mathrm{~cm}$, lâminas lanceoladas, $16-38 \times 0,5-10,5 \mathrm{~cm}$, base atenuada, ápice agudo, 3-7 nervuras. Inflorescência ramificada ou não, 45-176 × 1,7-2 cm, 2-18-ciclos, 1-4 flores cada; brácteas 3 , lanceoladas, $1,1-2,5 \times$ $0,5-1,7 \mathrm{~cm}$, Flores $0,4-1 \times 1,5-2 \mathrm{~cm}$, pedicelos $1-3 \mathrm{~cm}$; 3 sépalas $0,8-2 \times 0,3-0,5 \mathrm{~cm}$; pétalas brancas $0,4-0,6 \times 1-1,5 \mathrm{~cm}$; pistiladas carpelos amarelos; estaminadas, 24-45 estames, anteras 1-2 mm compr., filetes 3-4 mm compr. Aquênio, 2 mm compr., 1 glândula.

Material selecionado: Cabo Frio, 2.I.1951, C. Poland 6650 (RB). Campos dos Goytacazes, Lagoa Feia, lagoa Quim (-22.0368; -41.2478), 20.I.2015, Y.M. Canalli 78 \& A.V.Greco (R). Carapebus, PARNA Jurubatiba, Lagoa Paulista (-22.2390; -41.5647), 16.VII.2014, Y.M. Canalli et. al. 71 (R). Macaé, Restinga de Cabiúnas, 15.XI.1997, L.J.S. Pinto 71 (RFFP). Maricá, Restinga, 22.XI.1998, C.P. Bove et al. 338 (HUNI). Quissamã, PNRJ, lagoa Paulista, 31.VIII.2005, I.M. Silva et al (R09380). Rio de Janeiro, Reserva Biológica de Jacarepaguá, Lagoa Marapendi, 12.IV.1967, A.S. Moreira (GUA 5396).

Distribuída do sudeste dos Estados Unidos até o sul do Brasil (Haynes \& Holm-Nielsen 1994; Rego 1988). No Brasil ocorre no Amapá, Alagoas, Bahia, Paraíba, Sergipe, Espírito Santo e Rio de Janeiro (BFG 2915). No Rio de Janeiro ocorre nas quadrículas L34, M32, N30, O29, T27, T28, ao nível do mar, endêmica das restingas. Coletada com flores nos meses de janeiro a novembro.

5.3. Sagittaria montevidensis Cham. \& Schltdl., Linnaea 2: 156. 1827.

Fig. 3g-j

Ervas emergentes, monoicas, ca. $80 \mathrm{~cm}$ alt. . Folhas emersas, bainha 4-22 × 1,5-4,5 cm, pecíolo cilíndrico, 11-93 × 0,4-3 cm, lâminas ovadas, 4-37 × 1-33 cm, base sagitada, ápice obtuso, 3-25 nervuras. Inflorescência paniculada, ramificada ou não, 0,17-2,1 m compr., emersa, 5-16 ciclos, 1-13 flores cada; brácteas 3-muitas, conadas a livres, lanceoladas $0,6-1,4 \times 0,3-0,6 \mathrm{~cm}, 8-9$ nervuras. Flores $0,8-2 \times 2-3,5 \mathrm{~cm}$, pedicelo $0,5-9$ cm compr., 3 sépalas 1,1-2 $\times 0,4-1,8 \mathrm{~cm}$, nervuras numerosas, pétalas brancas com mácula vinácea na base 1,2-1,8 × 1-1,5 cm; pistiladas carpelos amarelos sem estaminódios; estaminadas, estames $\infty$, anteras $2 \mathrm{~mm}$ compr., filetes $4-5 \mathrm{~mm}$ compr., pistilódios ausentes. Aquênio 0,4-1,5 × 0,2-1,5 cm, 0-1 glândula.

Material selecionado: Araruama, São Vicente de Paula, Córrego com esgoto, -22.7190; -42.262), 5.XII.2014, Y.M. Canalli 76 \& A.V. Greco (R). Barra do Piraí, Ilha dos Amores do Itapoã Country Clube no rio Paraíba do Sul, 7.XI.1984, J.P.P. Carauta 4958 et al. (GUA). Barra Mansa, Ilha do Muri, no rio Paraíba do Sul, 5.XI.1984, J.P.P. Carauta 4893 et al. (GUA). Cabo Frio, Praia do Pontal, 17.IV.1952, L.B. Smith 6635 (R). Campos dos Goytacazes, Estrada para lagoa Feia, Barra do Furado, -22.0361; -41.2612, 20.I.2015, Y.M. Canalli 63 et al. (R). Itaboraí, João Caetano, próximo à BR-493, -22.7258, -42.9516, 19.VIII.2014, A.R. Lourenço 22 (R). Levy Gasparian, Distrito de Paraibuna, a margem do rio Paraibuna, na proximidade da produtora de energia elétrica Mont'Serrat Energética S.A., 22 01 '10.58'S, $43^{\circ} 18$ '24.42"W, 5.XI.2014, D.N.S. Machado 461 \& S.S. Medeiros (RFFP). Nova Iguaçu, Centro, via Light, córrego com esgoto (-22.755560, -43.460322) 19.VII.2015, Y.M. Canalli 95 \& A.V. Greco (R). Paraíba do Sul, Margens do rio Paraíba do Sul, 25.VII.1984, J.P.P. Carauta 4805 et al. (GUA). Piraí, reservatório Santana, próximo à fazenda Cel. Zeda, 27.II.1986, M.B. Casari 
1211 (GUA). Porto Real, rio Paraíba do Sul, 21.X.1981, J.P.P. Carauta 3850 et al. (GUA). Resende, Visconde de Mauá, córrego na beirada da estrada do lado direito, sentido Penedo-Mauá, -22.33113, -44.53546, 18.VII2015, Y.M. Canalli 94 \& A.V. Greco (R). Rio de Janeiro, Lagoa Rodrigo de Freitas, VIII.1913, F.C. Hoehne 120 (R). São Gonçalo, Jardim Catarina Velho, rua Emílio Fischer, vale ao lado do campo de futebol. Local conhecido como Baixada, -22.8019; -43.0066, 21.XII.2014, A.R. Lourenço 22 (R). Sapucaia, Anta, 27.IX.2003, C.P. Bove et al. 1208 (R). Seropédica, Rodovia Raphael Magalhães (-22.7875; -43.7724), 1.XI.2014, Y.M. Canalli 72 et al. (R). Teresópolis, Alagado próximo ao condomínio Sítio da Serra, BR 116, km 73,5, 14.VIII.2001, A.D.R. Moreira 128 (R). Três Rios, a montante dos rios Paraibuna, Piabanha e Paraíba do Sul, 26.IX.2003, C.P. Bove 1180 (R). Vassouras, Fazenda Galo Vermelho, Mata Atlântica secundária, 6.X.2000, W.B. Carvalho 193 \& L.O.F. Sousa (RFFP).

Distribuída do noroeste da América do Norte até noroeste do México, Equador e Peru, nordeste do Chile, Uruguai e sudeste do Brasil (Haynes \& Holm-Nielsen 1994). No Brasil ocorre no Acre, Mato Grosso do Sul, Rio de Janeiro, São Paulo e na região Sul (BFG 2015). No Rio de Janeiro ocorre nas quadrículas L20, L34, M13, M15, M17, O18, P5, P6, P10, P13, Q7, Q18, R10, R14, S12, S18, T27, U13, U24, 0-341 m alt. Coletada com flores durante todo o ano. Estes registros consistem em novas ocorrências para os municípios de Araruama, Nova Iguaçu, São Gonçalo, Seropédica e Resende.
5.4. Sagittaria rhombifolia Cham., Linnaea 10: 2191836.

Fig. 4a-c

Ervas ca. $80 \mathrm{~cm}$ alt., emergentes, monoicas. Folhas emersas, bainha 7-17,5 × 1,5-4 cm, pecíolo cilíndrico costado $6,5-59 \times 0,3-2 \mathrm{~cm}$, lâminas elípticas $5-27 \times 3,1-11,2 \mathrm{~cm}$, base cuneada, truncada ou cordada, ápice agudo a arredondado, 9-16 nervuras. Inflorescência emersa $31-71,5 \times 0,5-1,9 \mathrm{~cm}, 2-7$ ciclos, 1-3 flores cada; brácteas 3 lanceoladas, 1,5-4× 0,5-2,7 cm, nervuras numerosas. Flores 1-3,5 × 1,3-4 $\mathrm{cm}$, pedicelos $1,5-5 \times 0,1-0,8 \mathrm{~cm}$; sépalas $1,5-2,5$ $\times 0,5-2,1 \mathrm{~cm}$, nervuras numerosas; pétalas brancas ou amareladas, com máculas amarelas ou vináceas na base $1,1-1,2 \times 0,7-1,5 \mathrm{~cm}$; pistiladas, carpelos 2 mm compr., estilete ausente, estigma apical lateral; estaminadas, 12-14 estames, filete $2 \mathrm{~mm}$ compr., antera $2 \mathrm{~mm}$ compr. Aquênio com apículo lateral, $0,4-0,5 \times 0,2-0,3 \mathrm{~cm}$, sem glândulas.

Material selecionado: Campos dos Goytacazes, Lagoa de Cima, num canal que deságua na lagoa, 8.III.1983, M.B. Casari 924 \& D.S. Pedrosa 823 (GUA).

Material adicional: BRASIL. MATO GROSSO DO SUL: Município de Santa Rita do Rio Pardo, riacho afluente do rio Paraná na MS395, ca. $12 \mathrm{~km}$ NE de Bataguassu (2137'12,1"S; 52 $\left.21^{\circ} 21^{\prime \prime} \mathrm{W}\right)$, 25.VII.2014, C.P. Bove et al. 2401 (R). MINAS GERAIS: Triângulo mineiro, lagoa perto a Ituiutaba, 27.III.1959, Castellanos 22425 (R). Lagoa Santa, XI.1915, F.C. Hoehne 6364 (R). Município de Lagoa Santa, Lagoa Santa (1940'S, $43^{\circ} 55^{\prime}$ W), 3.V.1952, L.B. Smith et al. $6715(\mathrm{R})$.
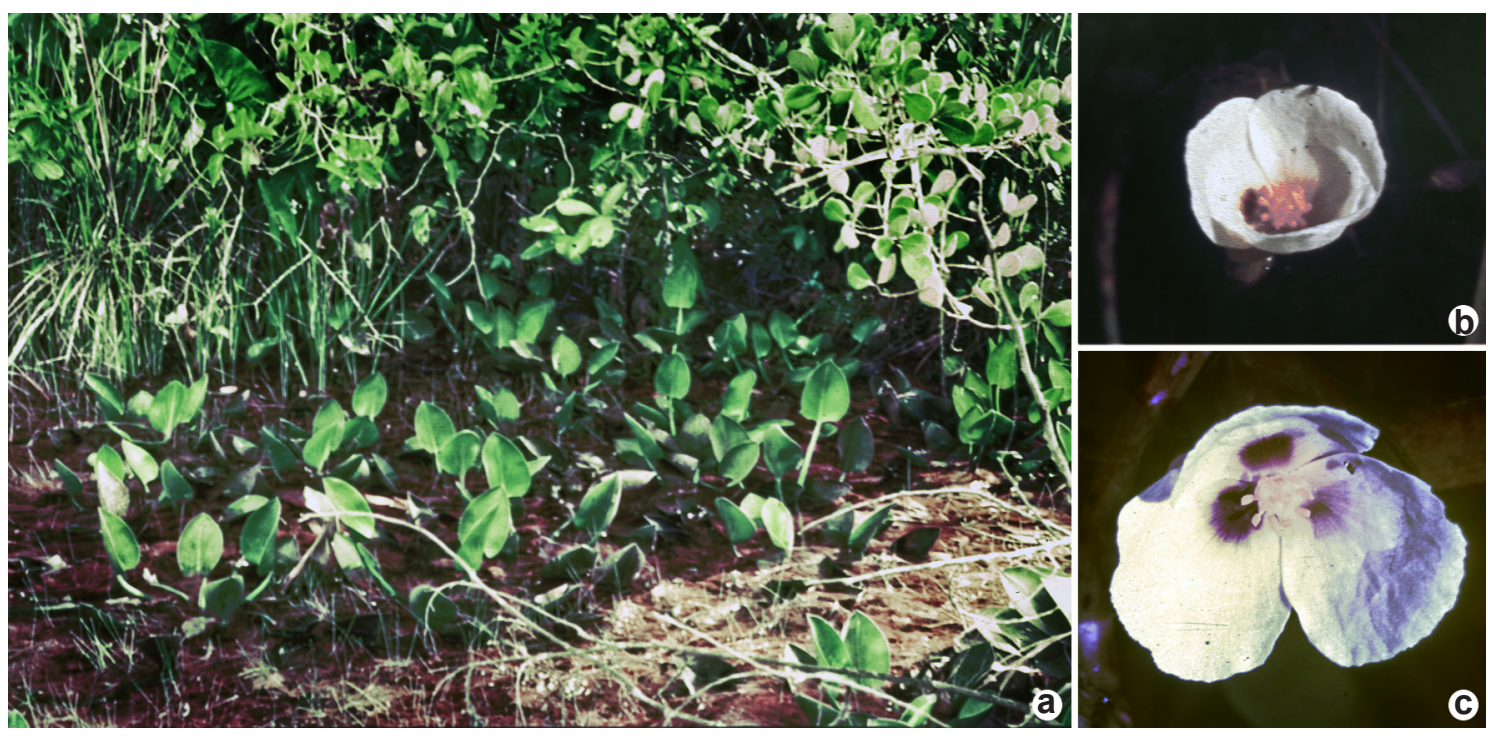

Figura 4 - a-c. Sagittaria rhombifolia - a. hábito; b. flor feminina; c. flor masculina (Bove 2401). Fotos: a-c. C.P. Bove. Figure 4 - a-c. Sagittaria rhombifolia - a. habitus; b. female flower; c. male flower (Bove 2401). Photos: a-c. C.P. Bove. 
Distribuição neotropical, da Venezuela até o Paraguai (Pott \& Pott 2000). No Brasil ocorre no Pará, Roraima, Tocantins, Bahia, Piauí, região Centro-Oeste, Minas Gerais, São Paulo e região Sul (BFG 2015). Sua ocorrência no Rio de Janeiro é aqui relatada de forma inédita, na quadrícula L34, 7 m alt. Encontrada com flores em março. Tentativas de novas coletas desta espécie no estado foram infrutíferas. As folhas podem ser utilizadas no tratamento de hérnia, inflamação dos testículos, picada de cobra e antitumoral (Thomaz et al. 2003).

\section{Agradecimentos}

Aos curadores e equipe dos herbários EAN, FFAR, GFJP, GUA, HPL, HRB, HUNI, R, RB, RBR, RFA, RFFP e VIES. A D.N.S. Machado, a foto de flor de Echinodorus grandiflorus. À CAPES, a bolsa de Mestrado de Y.M.C. À equipe do LAPLAQ, Pós-graduação em Botânica do Museu Nacional e Alexandre Verçosa Greco, o apoio durante o desenvolvimento do trabalho. Ao CNPq (edital PROTAX, Proc. 562251/2010-3 e bolsa de Produtividade de C.P.B.).

\section{Referências}

Abreu, L.C. 1981. Flora fanerogâmica da Reserva do Parque Estadual das Fontes do Ipiranga (São Paulo, Brasil). 162 Alismataceae. Hoehnea 9: 119-120.

Abreu, L.C. 1981. Flora fanerogâmica da Reserva do Parque Estadual das Fontes do Ipiranga (São Paulo, Brasil). 160 Butomaceae. Hoehnea 9: 118.

BFG. 2015. Growing knowledge: an overview of Seed Plant diversity in Brazil. Rodriguésia 66: 1085-1113.

Bogin, C. 1955. Revision of the genus Sagittaria (Alismataceae). Memoirs of the New York Botanical Garden 9: 179-233.

Burkill, H.M. 1985. The useful plants of west tropical Africa. Royal Botanic Gardens, Kew. Vol. 1. 976p.

Forni-Martins, E.R. \& Calligaris, K.P. 2002. Chromosomal studies on Neotropical Limnocharitaceae (Alismatales). Aquatic Botany 74: 33-41.

Guimarães, E.S. \& Mello-Silva, R. 2003. Flora de GrãoMongol, Minas Gerais: Alismataceae. Boletim de Botânica da Universidade de São Paulo 21: 55-56.

Haynes, R.R. \& Holm-Nielsen, L.B. 1992. The Limnocharitaceae. Flora Neotropica 56: 132.

Haynes, R.R. \& Holm-Nielsen, L.B. 1994. The Alismataceae. Flora Neotropica 64: 1-112.

Kinupp, W. F. \& Lorenzi, H. 2014. Plantas alimentícias não convencionais (PANC) no Brasil: guia de identificação, aspectos nutricionais e receitas ilustradas. Instituto Plantarum de Estudos da Flora, São Paulo. 768p.

Lehtonen, S. 2008. An integrative approach to species delimitation in Echinodorus (Alismataceae) and the description of two new species. Kew Bulletin 63: 525-563.

Lehtonen, S. \& Gordon, E. 2010. Atualización del conocimento de los géneros Echinodorus y Helanthium (Alismataceae) em Venezuela. Acta Botánica Venezuelica 33: 249-272.

Lehtonen, S. \& Myllys, L. 2008. Cladistic analysis of Echinodorus (Alismataceae): simultaneous analysis of molecular and morphological data. Cladistics 24: 218-239.

Matias, L.Q. 2007. O gênero Echinodorus no domínio da Caatinga brasileira. Rodriguésia 58: 743-774.

Matias, L.Q.; Lopes, R.C. \& Sakuragui, C.M. 2016. Alismataceae. In: Lista de espécies da flora do Brasil. Jardim Botânico do Rio de Janeiro. Disponivel em <http://floradobrasil.jbrj.gov.br/ jabot/floradobrasil/FB39>. Acesso em 18 janeiro 2016.

Matias, L.Q. \& Irgang, B.E. 2006. Taxonomy and distribution of Sagittaria (Alismataceae) in NorthEastern Brazil. Aquatic Botany 84: 183-190.

Matias, L.Q. \& Souza, D.J.L. 2011. Alismataceae no estado do Ceará, Brasil. Rodriguésia 62: 887-900.

Moreira, A.D.R. \& Bove, C.P. 2007. Alismataceae. In: Cavalcanti, T.B. \& Ramos, A.E. (orgs.). Flora do Distrito Federal 5: 15-27.

Moreira, A.D.R. \& Bove, C.P. 2010. Flórula do Parque Nacional da Restinga de Jurubatiba, Rio de Janeiro, Brasil: Alismataceae. Arquivos do Museu Nacional 68: 163-165.

Novelo, R.A. \& Lot, H.A. 1994. Alismataceae. In: Davidse, G.M.; Souza, S. \& Chater, A.O. (eds.). Flora Mesoamericana. Universidad Nacional Autónoma de México, México, D.F. Vol. 6, Pp.3-8.

Novelo, R.A. \& Lot, H.A. 1994. Limnocharitaceae. In: Davidse, G.M.; Souza, S. \& Chater, A.O. (eds.). Flora Mesoamericana Universidad Nacional Autónoma de México, México, D.F. vol. 6, Pp.8-12.

Pansarin, E.R. \& Amaral, M.C.E. 2002. Limnocharitaceae. In: Wanderley, M.G.L.; Shepherd, G.J. \& Giulietti, A.M. (coords.). Flora fanerogâmica do estado de São Paulo. Instituto de Botânica, São Paulo. Vol. 2. Pp.155-167.

Pansarin, E.R. \& Amaral, M.C.E. 2005. Alismataceae. In: Wanderley, M.G.L.; Shepherd, G.J. \& Giulietti, A.M. (coords.). Flora fanerogâmica do estado de São Paulo. Instituto de Botânica, São Paulo. Vol. 4. Pp.1-10.

Pedersen, T.M. \& Klein, R.M. 1976. Limnocaritáceas. In: R. Reitz (ed.). Flora Ilustrada Catarinense. Herbário Barbosa Rodrigues, Itajaí. Fasc. LIMN, 1-9 p.

Pott, V.J. \& Pott, A. 2000. Plantas aquáticas do Pantanal. Embrapa, Brasília, DF. 404p.

Rataj, K. 2004. A new revision of the swordplant genus Echinodorus Richard, 1848 (Alismataceae). Aqua Journal of Ichthyology and Aquatic Biology. Special Publication 1. 144p. 
Rego, S.C.A. 1988. Alismataceae Ventenat no Rio Grande do Sul. Dissertação de Mestrado. Universidade Federal do Rio Grande do Sul, Porto Alegre. 120p.

Seubert, M.A. 1847. Alismaceae. In: Martius C.P.F.; Eichler, A.W. \& Urban, I. Flora brasiliensis. Munchen, Wien, Lipsiae.. Vol. 3, pt 1, Pp. 101112, tab. 12-16.

Seubert, M.A. 1847. Butomaceae. In: Martius C.P.F.;
Eichler, A.W. \& Urban, I. Flora brasiliensis. Munchen, Wien, Lipsiae. Vol. 3, pt 1, p. 113-118, tab. $13,16$.

Thomaz, D.O.; Costa Neto, S.V. \& Tostes, L.C.L. 2003. Inventário florístico das ressacas das bacias do Igarapé da Fortaleza e do Rio Curiaú. Diagnóstico das ressacas do estado da Amapá: bacias do Igarapé da Fortaleza e Rio Curiaú, Macapá. CPAQ/IEPA e DGEO/SEMA, Macapá. 22p.

\section{Lista de exsicatas}

Andrade, A.G. 10 (1.1), 23 (4.1), 1174 (2.1). Anjos, R. 10 (1.1), 37 (5.2). Araújo, D. 1339 (1.2), 3260 (5.3), 3434 (3.1), 3453 (5.2), 4326 (4.1). Armond, N. s.n. (R 4422) (1.1), 135 (1.1). Barcia, J. 490 (1.1). Barros. A.A.M. 4353 (3.1). Bastos, S. 4 (4.1). B.M.B.L. 18 (4.1), 25 (4.1). Braz, D.S. 13 (1.1). Bove, C.P. 95 (5.1), 128 (5.2), 129 (5.2), 189 (5.1), 200 (5.1), 276 (31), 281 (5.1), 308 (5.1), 338 (5.2), 339 (5.2), 401 (5.2), 402 (5.2), 443 (4.1), 444 (1.1), 410 (5.2), 550 (2.1), 816 (5.1), 969 (5.1), 1063 (3.1), 1100 (1.1), 1180 (5.3), 1208 (5.3), 1211 (5.3), 1309 (5.2), 1398 (3.1), 1414 (5.3), 1415 (5.3), 1597 (5.2), 1761 (5.2), 2401 (5.4). Brade, A.C. s.n. (R 216772) (3.1), s.n. (2.1) (R36051). Braga, P.I.S. 1537 (5.3). Canalli, Y.M. 59 (1.1), 60 (3.1), 62 (3.1), 63 (5.3), 65 (5.3), 71 (5.2), 72 (5.3), 73 (1.1), 76 (5.3), 77 (5.3), 78 (5.2), 79 (4.1), 80 (4.1), 81 (3.1), 82 (4.1), 83 (3.1), 84 (1.2), 85 (1.2), 86 (1.2), 87 (5.3), 88 (3.1), $90(5.3), 91$ (5.3), 92 (3.1), 93 (5.3), 94 (5.3), 95 (5.3). Carauta, J.P.P. s.n. (GUA 27202) (1.1), 2468 (3.1), 3850 (5.3), 3870 (1.1), 4664 (4.1), 4805 (5.3), 4893 (5.3), 4958 (5.3), 5053 (1.1), 5166 (5.3), 5256 (5.3). Carrijo, T.T.: 50 (4.1). Carvalho, W.B. 193 (5.3). Casari, M.B. 469 (3.1), 585 (5.1), 615 (1.2), 518 (3.1), 519 (5.3), 522 (5.3), 569 (5.3), 573 (4.1), 602 (3.1), 639 (3.1), 653 (5.3), 924 (5.4), 978 (5.2), 979 (5.2), 1211 (5.3). Castellanos 22425 (5.4). Corrêa, M. 42042 (5.2). Emmerich, M. 161 (4.1). Freire, C.V. s.n. (R 52927) (3.1), s.n. (R 52928) (4.1), s.n. (R 36052) (1.1), s.n. (R 36052). Gil, A. 18 (1.2). Goés, G.C. 28 (1.1). Goés, O.C. s.n. (RB 49368) (1.1). Guedes, M.L. 19645 (5.2). Guimarães, E. 1 (5.3), 1436 (1.2). Guimarães, E.S. 24 (2.1), 44(1.2). Hoehne, F.C. 120 (5.3), 6364 (5.4). Hottz, D. 262 (1.2). Lima, H.C. 4548 (1.2). Lutz, A. 38 (5.1), 1767 (2.1). Lutz, B. 1663 (3.1). Lourenço. A.R. 22 (5.3), 23 (4.1), 55 (3.1). Machado, D.N.S. 461 (5.3), 752 (4.1). Martinelli, G. 8823 (1.2). Mattos, M. s.n. (R 52930) (4.1). Mendes, T.S. 82 (1.1). Monteiro, H. s.n. (RBR 28879) (1.2). Monteiro, S. s.n. (RB 463801) (1.1). Moreira, A.D.R. 11 (5.2), 24 (5.3), 25 (5.3), 40 (4.1), 41 (1.1), 49 (4.1), 50 (1.1), 128 (5.3), 134 (1.1). Moreira, A.S. s.n. (GUA 5396) (5.2). Moreira, C.B. 50 (3.1). Pastana, G.I.I. 19 (5.3). Paz, J. 512 (5.2), 514 (5.2). Pereira, F.B. 09/129 (1.1). Pereira, V. 70 (1.2). Pinto, L.J.S. 71 (5.2). Poland, C. 6650 (5.2). Queiroz, E.P. 1775 (2.1). Rego, S.A. 1193 (1.1). Rodrigues, R.R. Jr. 11 (3.1). Sacco, C. 1882 (5.3). Sampaio, A. 3086 (2.1). Sampaio, A.J. 9001 (5.3). Santo, I.E. 144 (3.1). Santos, M.G. 2083 (4.1). Schwacke 1406 (3.1), 5603 (3.1). Segadas-Vianna, F.I. 1313 (2.1). Sem coletor s.n. (R 216767) (3.1), s.n. (R 216767) (3.1), s.n. (RFA 21223) (3.1). Silva, I.C. 92 (5.1). Silva, I.M. s.n. (R 209380) (5.2), 245 (5.2), 725 (5.2). Silva, M.M. 203 (1.1). Silva, Z. s.n. (R 214053) (5.2), s.n. (R 214054) (5.3), s.n. (R 217215) (4.1). Smith, L.B. 716635 (5.3), 6715 (5.4). Stalcup, M. 112 (1.1). Strang, H.E. 344 (5.2). Sucre, D. 1424 (3.1), 5275 (5.3). Sylvestre, L. 109 (5.3). Ule, E. 31468 (5.2). Vale, F.H.A. s.n. (R 161280) (1.1). Vianna, M.C. 2173 (5.3). Zippin, M. s.n. (GUA 30389) (5.3), 51 (5.3), 56 (3.1). 